\title{
Predictors of compliance with short-term treatment among patients with back pain
}

\author{
Neusa Maria Costa Alexandre, ${ }^{1}$ Margareta Nordin, ${ }^{2}$ Rudi Hiebert, ${ }^{2}$ \\ and Marco Campello ${ }^{2}$
}

ABSTRACT Objective. Great efforts have been made to find effective treatments for back pain. Nevertheless, the effectiveness of a particular treatment can depend on patient compliance. The objective of this study was to prospectively investigate whether patients' demographic factors, clinical factors, external barriers in following the treatment, and perceptions of disability, quality of life, depression, and control over health were predictive of compliance with a physical therapy program carried out with patients with low back pain.

Methods. This was an exploratory prospective cohort study that was carried out in New York City during 1999. All study participants answered a questionnaire at the initial clinical evaluation by a physical therapist and were followed during the treatment. The study assessed compliance with the three treatment regimens that were prescribed for every patient: attending scheduled physical therapy sessions, following a program of home exercises, and watching back-education videotapes. Depending on the individual patient, the planned treatment program could last from 2 to 6 weeks. The study employed a battery of instruments to measure patient characteristics that included perceived functional limitations, perceived quality of life, depression, and their beliefs about their health. Student's t tests and chi-square tests were used to determine if non-and low-compliant patients differed significantly from high-compliant patients. Logistic regression was used to estimate adjusted odds ratios expressing the association of selected variables with compliance.

Results. We found that $51 \%$ of the patients were either noncompliant or low-compliant overall with the low back pain treatment program. There were differences in compliance behavior among the three treatment regimens, with compliance being highest for watching the back-education videotapes and lowest for doing the home exercises. Poor compliance overall was positively associated with the expectation of barriers in following the proposed treatment, with comorbidity, and with longer duration of treatment in this program.

Conclusions. The findings of our study indicate that patient compliance with back pain treatment is a serious and complex problem. Nevertheless, while this study was only an exploratory one, we believe that the results of this study can be used by care providers to identify patients likely to become noncompliant and also by researchers to plan specific studies on the effectiveness of treatment programs for patients with low back pain.

Key words Low back pain, therapeutics, patient compliance, health behavior, patient education.

1 State University of Campinas, School of Medical Sciences, Department of Nursing, Campinas, São Paulo, Brazil. Send correspondence to: Neusa Maria Costa Alexandre, Department of Nursing, School of Medical Sciences, State University of Campinas, Campinas, São Paulo, Brazil; e-mail: neusalex@fcm.unicamp.br

2 Mount Sinai NYU Health, Hospital for Joint Diseases, Occupational and Industrial Orthopaedic Center, New York, New York, United States of America.
Musculoskeletal disorders, especially back pain, are an important public health problem and are the most frequent cause of activity limitation in people below age 45, according to studies in industrialized countries (1-4). The escalation of low back problems has continued despite ergonomic and technological developments. And while studies on the dimensions of this problem are still needed for many developing countries, there is a growing concern about the proportion of and socioeconomic consequences from low back pain in the countries of Latin America and the Caribbean as well. 
Great efforts have been made to improve the efficacy of treatment in patients diagnosed with low back pain in industrialized countries. Guidelines for the treatment of low back pain have been developed to improve patient care and to reduce costs. This approach has also influenced researchers and other professionals in developing countries. However, the effectiveness of a particular treatment may be dependent upon patient compliance. As defined by Haynes et al. (5), compliance is "the extent to which a person's behavior (in terms of taking medications, following diets, or achieving lifestyle changes) coincides with advice from physicians or other health care providers." Agras (6) suggested that there are five main components of compliance behavior: 1) entering into treatment, 2) keeping appointments, 3) taking medication and correctly performing home-based therapeutic regimens, 4) making lifestyle changes, and 5) avoiding health-risk behaviors. Recently, there has been a discussion in the scientific literature of the implications and connotations of the terms "compliance" and "adherence" (7, 8). Kroll et al. (9) reported that the two terms tend to be used interchangeably and that they can be defined as "an active process, in which the patient works to maintain their health in close collaboration with health care providers."

Reports in the literature demonstrate that poor compliance with therapeutic regimens is a serious problem for patients with a wide range of diagnoses and who are receiving treatment in various settings (10-13). Kroll et al. (9) summarized factors that have been identified as causes for nonadherence: cognitive-emotional, behavioral, cultural, social and family-related, disease-related, treatment-related, and organizational and economic. More attention should be given to compliance issues because the consequences of noncompliance with suggested treatment can be serious, including exacerbation and progression of disability, development of secondary complications, more frequent medical emergencies, unnecessary prescription of drugs, and a general failure of expected treatment outcomes (14).

\section{Back pain and compliance}

General aspects of back pain treatment have been studied, including rehabilitation, outcome, disability, and compliance. The prescribed treatments for back pain are various and can include home exercise therapy, returning to work, practice of muscular relaxation, weight reduction, ergonomic education, physical therapy appointments, and alterations in activities of daily living (15). Health care providers need to address the problem of poor compliance with treatment for patients with low back pain, and the providers also need to examine compliance rates with all the various prescribed therapies. Lawrence et al. (16) noted that relatively little is known specifically about patient compliance with back pain treatment.

For our study we hypothesized that both external and internal factors can affect treatment compliance for patients with low back pain. In a thorough literature review we found only limited information concerning patient adherence to noninvasive treatment. No study was found that directly investigated compliance with education and exercise regimens for patients diagnosed with low back pain.

The purpose of this study was therefore exploratory. The study identifies predictors of treatment compliance among a convenience sample of patients with low back pain. We prospectively examined whether a number of different factors were associated with compliance with an education and exercise regimen. Among the factors we investigated were demographic factors, clinical factors, and external barriers as well as patients' perceptions of disability, quality of life, depression, and control of their health.

\section{METHODS}

\section{Definitions}

For our study we defined compliance as the extent to which a patient's behavior coincided with a clinical prescription (17). Our study focused on compliance with a specified regimen within a short and limited period of treatment (18). We use the terms "adherence" and "compliance" interchangeably in this paper. We defined noncompliance as not adhering to prescribed physical therapy appointments, educational activities, and/or a home exercise regimen.

\section{Procedure}

This was an exploratory prospective cohort study that was conducted in 1999. We drew from a convenience sample of patients visiting the Occupational and Industrial Orthopaedic Center (OIOC) of the Hospital for Joint Diseases of Mount Sinai NYU Health. Located in New York City, the OIOC is a research outpatient clinical center that specializes in treating patients with low back pain. Patients are referred to this clinic from community physicians and osteopaths, hospitals, occupational health care facilities, selfreferrals, and other sources.

The patients who agreed to participate in this study completed a questionnaire following their first physical therapy appointment, which included a thorough clinical evaluation. The treatment prescribed for these patients consisted of three regimens: 1) an active physical exercise program on site supervised by a physical therapist during the therapy sessions, 2) back education through videotapes at the OIOC, and 3) a home exercise program. After conducting the clinical evaluation for each patient, the physical therapist set goals and a treatment plan that included the recommended number of physical therapy sessions on site, the home exercise plan, and the number of back education videos to be watched. The number of physical therapy treatment sessions for individual patients could range from 6 to 12 sessions. The home exercise plan and the number of videos to be watched were individually set by the physical therapist. The videos covered such topics as the basics of spinal anatomy, body mechanics, causes of back pain, postural orientation, and exercises. Depending on the overall plan 
for each patient, the entire treatment program could range from 2 to 6 weeks.

\section{Measurement of compliance}

This study used three indicators of compliance: attendance at the scheduled physical therapy sessions, performing the home exercises, and watching the educational videotapes.

Attendance at scheduled physical therapy sessions was assessed according to the percentage of scheduled appointments that were kept, with a possible score of 0,1 , or 2 points. Compliance was scored as "high compliance" (2 points) for attending at least $80 \%$ of the scheduled sessions, as "low compliance" (1 point) for attending at least one of the sessions but less than $80 \%$ of them, and as "no compliance" (0 points) for attending none of the scheduled sessions. These criteria were chosen after discussion with the treating physical therapists, who indicated that lower than $80 \%$ compliance with the suggested treatment plan might not yield a positive treatment outcome.

Home exercise was self-reported by means of a patient diary, with patients receiving a diary sheet each week on which to record the frequency of the exercises that they performed at home. Similar to attendance at the scheduled physical therapy sessions, compliance with the home exercise regimen was scored as 0,1 , or 2 points, according to the mean value of the number of exercises done per week during the weeks of treatment in comparison to the recommended number of exercises. Compliance was scored as "high compliance" (2 points) for doing at least $80 \%$ of the exercises, as "low compliance" (1 point) for doing some but less than $80 \%$ of the exercises, and "no compliance" (0 points) for doing none of the exercises. As before, these criteria were set after discussion with the physical therapists.

Education by videotape (back education) was assessed according to the percentage of recommended videos actually watched, again with possible scores of 0,1 , or 2 points. Compliance was scored as "high compliance" (2 points) for watching at least $80 \%$ of the recommended videos, "low compliance" (1 point) for watching some but less than $80 \%$ of the recommended number, and "no compliance" (0 points) for not watching any of the recommended videos. These criteria were chosen after discussion with the treating physical therapists at OIOC.

In order to perform the statistical analysis, the three compliance scores were added and were then categorized into three levels. The range of possible total scores was 0 to 6 . The data were categorized as "high compliance" for a score of 5 or 6 , "low compliance" for a score of 1 to 4 , and "noncompliance" for a score of 0 .

\section{Other measures}

Self-report questionnaires and patients' charts were used to collect data for this study. At first visit, data were requested concerning demographic characteristics, health and back-pain history, and external barriers to following the prescribed treatment.

The demographic data included age, gender, marital status, and education. Also collected was information on previous history of low back pain and of treatment for it, and current comorbidity. The data about treatment duration ( 2 to 6 weeks) were collected over the course of the OIOC treatment sessions.

The external barriers were of two types: 1) living alone and 2) having foreseeable problems in following the proposed treatment. According to reports in the scientific literature, these two barriers can affect treatment compliance. At first visit, the participants were asked if they lived alone and also asked to cite one foreseeable, potential obstacle to following the proposed treatment. These problems included family dependency, transportation difficulties, work schedule, lack of time, financial problems, and need for child care.

Patient perceptions of pain, disability, quality of life, depression, and control over their health were measured as described below.

Pain intensity was measured by a numerical rating scale of 0 to 100 , with
0 indicating no pain and 100 indicating the worst pain imaginable (19).

The patient's perceived functional limitation was measured by the Oswestry low back pain disability scale. The overall Oswestry score is obtained by scaling the sum of the component scores on an ordinal scale from 0 to 100 . The Oswestry scale has been validated for use with patients with low back pain and has high reliability $(14,20,21)$.

The Spitzer Quality of Life Index was used to measure the patient's perception of quality of life. The index is comprised of five items with three responses, each scored on scale of 0,1 , or 2 points, giving a maximum score of 10 . The index has been used successfully to measure the general wellbeing of patients with cancer and other diseases and has been well validated $(21,22)$.

Depression was assessed by using the Center for Epidemiological Studies Depression Scale (CES-D). The CES-D Scale is a 20-item measure that was tested as a measure of depressive symptomatology for use in studies of the general population. The possible range of scores is 0 to 60 , with the higher scores indicating more symptoms, weighed by the frequency of occurrence during the past week. Studies have indicated that the CES-D is internally consistent, has an acceptable testretest reliability, and has high construct validity (23-25).

The Multidimensional Health Locus of Control (MHLC) questionnaire was used to assess patients' beliefs about their health. This questionnaire has 18 questions that assess the extent to which subjects perceive their health as dependent on their own actions (internal scale), the actions of powerful others (powerful others scale), or chance factors (chance scale). This scale has been used to measure the beliefs of patients with low back pain, and studies have found evidence of the construct validity of the scale (26-29).

\section{Subjects}

The subjects in this study were patients referred during a period of 6 
months to the Occupational and Industrial Orthopedic Center (OIOC) of the Hospital for Joint Diseases of Mount Sinai NYU Health. All patients between the ages of 18 and 80 who visited the OIOC with acute or chronic nonspecific low back pain as a primary diagnosis were invited to participate in the study at the time of their initial clinical evaluation by a physical therapist. Nonspecific low back pain was identified by the clinical staff at OIOC based on the following codes from the International Classification of Diseases, Ninth Revision (ICD-9): intervertebral disc disorders (722.10, 722.2, 722.90 , and 722.93), other and unspecified disorders of the back (724.2, 724.3, and 724.5-9), sprains and strains of the sacroiliac region (846.0-9), and sprains and strains of other and unspecified parts of the back (847.2-9).

Participation in this study was voluntary, and all subjects who agreed to participate were asked to sign a consent form. The existing pattern of clinic visits was not altered for the purpose of this study. Exclusion criteria for the study included cases in which back pain was associated with the following: pregnancy, vertebral fractures/ trauma, spine surgery, spinal infections and spinal tumors, or systemic diseases. Language obstacles and/or illiteracy were also grounds for exclusion.

\section{The independent evaluator}

The independent evaluator for our study was a nurse who did not interfere in the proposed treatment. The evaluator was responsible for data collection, data quality, and the confidentiality of the collected data. The OIOC staff members were aware of the study and alerted the evaluator when a patient diagnosed with nonspecific low back pain was scheduled for physical therapy treatment. After the initial evaluation of the patient by the physical therapist, the evaluator explained the study and collected the patient's signed consent form. The independent evaluator observed the participating patients during all the physical therapy treatment sessions but did not in- terfere in the proposed treatment plan or the treatment itself. A log sheet was used to individually monitor each patient. The same independent evaluator was maintained throughout the study.

\section{Ethical considerations}

All patients who participated in this study were asked to provide written consent. The full protocol received approval from the Institutional Review Board of New York University Medical Center (NYUMC) (IRB-NYUMC: HJD 20 - 106/Protocol H 7773-03).

\section{Statistical analyses}

Descriptive statistics were used to describe the sample. In order to facilitate the analysis, noncompliant and low-compliant patients were grouped together and compared with highcompliant patients. The Student's $t$ test for independent samples and the chisquare test were used to test for differences between groups of subjects categorized as non-/low-compliant or as high-compliant, for continuous and categorical variables, respectively (30). Alpha was set at 0.05 for all tests of statistical significance. Logistic regression was used to estimate the adjusted odds ratios expressing the association that gender, marital status, duration of the treatment, presence of other medical illnesses, and foreseeable problems in following the prescribed treatment had with subsequent compliance with the prescribed treatment protocol. The statistical analysis was done using StatSoft STATISTICA for Windows software (31).

\section{RESULTS}

\section{Description of the sample}

Of the 128 patients who were invited to participate in this study, 5 refused and 3 were lost to follow-up. The total study sample therefore included 120 subjects, $76(63 \%)$ of whom were female and $44(37 \%)$ of whom were male. The median age was 46.5 years (standard deviation (SD), 12.2 years), and a large majority of the subjects were single $(73 \%)$.

\section{Description of the indicators of compliance with the treatment of low back pain}

With regard to the range of total scores, the analysis showed that, in overall terms, there were 11 noncompliant patients (9\%), 50 low-compliant ones $(42 \%)$, and 59 high-compliant ones $(49 \%)$.

Table 1 presents the compliance data broken out for the indicators for the three regimens: attending scheduled physical therapy sessions, participating in back education (watching videotapes), and doing the home exercises.

There were differences in compliance behavior among the three treatment regimens. A very slight majority $(51 \%)$ of the patients were rated as high-compliant with the scheduled physical therapy appointments, and $59 \%$ were high-compliant with educa-

TABLE 1. Treatment compliance among 120 patients with low back pain, New York City, 1999

\begin{tabular}{|c|c|c|c|c|c|c|}
\hline \multirow[b]{3}{*}{ Indicators of compliance } & \multicolumn{6}{|c|}{ Compliance } \\
\hline & \multicolumn{2}{|c|}{ None } & \multicolumn{2}{|c|}{ Low } & \multicolumn{2}{|c|}{ High } \\
\hline & No. & $\%$ & No. & $\%$ & No. & $\%$ \\
\hline \multicolumn{7}{|c|}{ Attending scheduled physical therapy } \\
\hline sessions & 11 & 9 & 48 & 40 & 61 & 51 \\
\hline Watching back-education videos & 12 & 10 & 37 & 31 & 71 & 59 \\
\hline Doing home exercises & 27 & 23 & 51 & 42 & 42 & 35 \\
\hline
\end{tabular}


tion by videotape. However, only 35\% of the patients were high-compliant with the recommended home exercise program.

\section{Compliance related to demographic characteristics of the patient}

Noncompliant and low-compliant patients were grouped together and compared with high-compliant patients in order to determine factors that could show differences between the two groups. The relationship between the demographic characteristics and the compliance rate is shown in Table 2. The relationship between compliance and factors such as age, gender, marital status, and education was examined by calculating chi-squares and Student's $t$ tests. As indicated in Table 2, two characteristics were statistically significant. Males were more compliant than female patients were, and married patients were more likely than unmarried patients to comply with the prescribed treatment.

\section{Compliance related to health and back pain history}

Table 3 compares rates of compliance with the previous history and treatment for low back pain, treatment duration, pain intensity, quality of life, perceived functional disability, and the presence of other medical conditions. The duration of treatment was significantly associated with compliance, with there being a lower rate of compliance with longer treatment. Comorbidity such as diabetes or hypertension was also associated with poor compliance. On the other hand, we found no statistically significant differences between the two groups in relation to pain intensity, quality of life, and perception of disability.

\section{Compliance related to external barriers}

The next set of analyses examined external barriers that might influence compliance (Table 4). The data in Table 4 indicate there was no statistically significant link between living alone and compliance. However, we did find an association between the patients' perception of foreseeable obstacles to following the prescribed treatment and their compliance. At first evaluation, when participants were asked to cite one foreseeable, potential obstacle to following the proposed program, their answers included: transportation $(45 \%)$, need for child care $(13 \%)$, work schedule $(13 \%)$, lack of time $(11 \%)$, family dependence (6\%), and financial problems (6\%).

\section{Compliance related to depression and patients' health beliefs}

Finally, we attempted to assess if compliance was related to depression or to patients' health beliefs (Table 5). We found no significant association between compliance and either depression or health locus of control beliefs.

TABLE 2. Relationship between demographic characteristics of the 120 patients with low back pain and their compliance with treatment, New York City, 1999

\begin{tabular}{|c|c|c|c|c|c|}
\hline \multirow{3}{*}{$\frac{\text { Patient characteristics }}{\text { Age (years) (mean, SD) }}$} & \multicolumn{4}{|c|}{ Compliance } & \multirow{3}{*}{$\frac{P \text { value }}{0.090}$} \\
\hline & \multicolumn{2}{|c|}{ Non-/Low-compliant } & \multicolumn{2}{|c|}{ High-compliant } & \\
\hline & 44.2 & $(12.2)$ & 48 & $(12.1)$ & \\
\hline Gender (no., \%) & & & & & 0.042 \\
\hline Female & 44 & 58 & 32 & 42 & \\
\hline Male & 17 & 40 & 27 & 60 & \\
\hline Marital status (no., \%) & & & & & 0.012 \\
\hline Single/Other & 42 & 55 & 35 & 45 & \\
\hline Married & 19 & 44 & 24 & 56 & \\
\hline Education (no., \%) & & & & & 0.510 \\
\hline Less than high school (HS) & 22 & 46 & 26 & 54 & \\
\hline Some high school/HS diploma & 11 & 48 & 12 & 52 & \\
\hline Some college/college degree & 28 & 57 & 21 & 43 & \\
\hline
\end{tabular}

a $\mathrm{SD}=$ standard deviation.

TABLE 3. Relationship that health history and low back pain (LBP) history had with treatment program compliance, 120 patients, New York City, 1999

\begin{tabular}{|c|c|c|c|c|c|}
\hline \multirow[b]{3}{*}{ Health and LBP history } & \multicolumn{4}{|c|}{ Compliance } & \multirow[b]{3}{*}{$P$ value } \\
\hline & \multicolumn{2}{|c|}{ Non/Low } & \multicolumn{2}{|c|}{ High } & \\
\hline & No. & $\%$ & No. & $\%$ & \\
\hline Previous history of LBP (no., \%) & & & & & 0.895 \\
\hline Yes & 48 & 51 & 47 & 49 & \\
\hline No & 13 & 52 & 12 & 48 & \\
\hline Previous treatment (no., \%) & & & & & 0.962 \\
\hline Yes & 38 & 51 & 37 & 49 & \\
\hline No & 23 & 51 & 22 & 49 & \\
\hline Treatment duration (no., \%) & & & & & $<0.001$ \\
\hline 2-3 weeks & 11 & 31 & 24 & 69 & \\
\hline 4 weeks & 19 & 49 & 20 & 51 & \\
\hline $5-6$ weeks & 31 & 67 & 15 & 33 & \\
\hline Other medical condition (no., \%) & & & & & 0.005 \\
\hline Yes & 27 & 69 & 12 & 31 & \\
\hline No & 34 & 42 & 47 & 58 & \\
\hline Pain intensity (mean, SD)a & 68.7 & $(27.8)$ & 65.9 & $(25.7)$ & 0.572 \\
\hline Quality of life (mean, SD) & 6.2 & $(2.5)$ & 6.6 & $(2.0)$ & 0.388 \\
\hline Disability (mean, SD) & 36.3 & $(10.1)$ & 35.9 & $(9.8)$ & 0.896 \\
\hline
\end{tabular}


TABLE 4. Relationship between external barriers to performing the proposed program and compliance for 120 patients with low back pain, New York City, 1999

\begin{tabular}{|c|c|c|c|c|c|}
\hline \multirow[b]{3}{*}{ Barrier } & \multicolumn{4}{|c|}{ Compliance } & \multirow[b]{3}{*}{$P$ value } \\
\hline & \multicolumn{2}{|c|}{ Non/Low } & \multicolumn{2}{|c|}{ High } & \\
\hline & No. & $\%$ & No. & $\%$ & \\
\hline Live alone & & & & & 0.788 \\
\hline Yes & 20 & 53 & 18 & 47 & \\
\hline No & 41 & 50 & 41 & 50 & \\
\hline $\begin{array}{l}\text { Foreseeable problems in following the } \\
\text { proposed program }\end{array}$ & & & & & $<0.001$ \\
\hline Yes & 25 & 81 & 6 & 19 & \\
\hline No & 36 & 41 & 53 & 59 & \\
\hline
\end{tabular}

TABLE 5. Relationship that depression and health beliefs had with compliance with treatment for low back pain, New York City, 1999

\begin{tabular}{|c|c|c|c|c|c|}
\hline \multirow[b]{3}{*}{ Depression and health beliefs } & \multicolumn{4}{|c|}{ Compliance } & \multirow[b]{3}{*}{$P$ value } \\
\hline & \multicolumn{2}{|c|}{ Non/Low } & \multicolumn{2}{|l|}{ High } & \\
\hline & Mean score & $S D^{a}$ & Mean score & SD & \\
\hline Depression & 22.7 & $(13.8)$ & 20.2 & $(14.5)$ & 0.326 \\
\hline \multicolumn{6}{|l|}{ Health beliefs } \\
\hline Internal Health Locus of Control & 25.3 & $(4.8)$ & 24.6 & $(5.5)$ & 0.471 \\
\hline Powerful Others Health Locus of Control & 25.1 & (5.3) & 23.9 & (6.6) & 0.255 \\
\hline Chance Health Locus of Control & 19.4 & (6.3) & 18.1 & (6.8) & 0.284 \\
\hline
\end{tabular}

a $\mathrm{SD}=$ standard deviation.

TABLE 6. Compliance with low back pain treatment, using logistic regression for selected predictors, New York City, 1999a

\begin{tabular}{lccc}
\hline \multicolumn{1}{c}{ Predictor of compliance } & $\begin{array}{c}95 \% \\
\text { Odds ratio } \\
(\mathrm{OR})\end{array}$ & $\begin{array}{c}\text { confidence } \\
\text { interval for OR }\end{array}$ & $P$ value \\
\hline $\begin{array}{l}\text { Gender (male) } \\
\text { Marital status (married) }\end{array}$ & 1.3 & $0.5-3.8$ & 0.61 \\
$\begin{array}{l}\text { Treatment duration } \\
4 \text { weeks }\end{array}$ & 1.5 & $0.5-4.0$ & 0.43 \\
$5-6$ weeks & 0.4 & $0.1-1.2$ & 0.11 \\
$\begin{array}{l}\text { Comorbidity present } \\
\text { Patient does not foresee difficulty with }\end{array}$ & 0.3 & $0.0-0.9$ & 0.03 \\
$\quad$ treatment plan & 0.3 & $0.1-0.9$ & 0.03 \\
\hline $\begin{array}{l}\text { a The reference groups for the odds ratios are: female, single/other, treatment duration of 2-3 weeks, no concur- } \\
\text { rent comorbidity condition, and foresees difficulty with proposed plan of treatment. }\end{array}$ &
\end{tabular}

\section{Predictors of compliance with treatment for low back pain}

We then used logistic regression to evaluate the extent to which gender, marital status, duration of the treatment, presence of other medical ill- nesses, and expected difficulties in following the proposed physical therapy program would predict compliance with treatment for low back pain. Using multivariate logistic regression analysis, we assessed the ability of these variables to predict high compli- ance. The data, which partially confirmed the previous results, are presented in Table 6.

Not expecting difficulty in following the proposed treatment was the strongest predictor for a high rate of compliance. The presence of other medical illnesses and a treatment duration of 5-6 weeks both showed a significant association with poor compliance. Gender and marital status were not related to the rates of high compliance.

\section{DISCUSSION}

Our results in this exploratory study showed that poor compliance with low back pain treatment was common and problematic. According to other researchers $(17,32)$, compliance rates vary from $10 \%$ to $85 \%$, depending on the population, the disease and regimen, and the definition of compliance that is used. From $30 \%$ to $50 \%$ of hypertension patients are noncompliant with a prescribed medication (11), and $50 \%$ of patients discontinue their participation in cardiac rehabilitation programs within the first year (33). We found that $51 \%$ of the patients in our study were noncompliant or low-compliant with overall treatment for low back pain. Friedrich et al. (34), studying exercise and motivation with chronic low back pain, found that only $51 \%$ of patients in a control group attended all of the 10 prescribed physical therapy sessions. This is in spite of the fact that other studies have indicated that patient compliance in attending the prescribed number of physical therapy sessions results in a positive outcome $(35,36)$.

Our results also showed differences in compliance behavior according to each specific treatment regimen for low back pain. In studies of other illnesses, other researchers have also found differing rates of compliance for such regimens as lifestyle recommendations, medication, scheduled tests, fluid restrictions, taking vital signs, exercise, and diet $(37,38)$.

In evaluating adherence with the home exercises, we found that only $35 \%$ of the patients were high-compli- 
ant with the prescribed regimen. Other studies, for patients with other diseases and treatments, have also shown poor adherence to recommended exercise programs $(13,25)$. Several studies have attempted to identify factors, beliefs, and attitudes that influence exercise adherence (39-41). There are indications that exercise adherence in low back pain treatment is as poor as with other diseases or treatments (42-44). Spelman (43) reported that only $30 \%$ of patients were compliant with a back exercise regimen.

The scientific literature has presented contradictory findings regarding treatment adherence and demographic characteristics $(32,43)$. In examining our data about demographics and compliance, our first results showed that compliance was associated with gender and marital status. However, since these association were not statistically significant according to our subsequent regression analysis, these two variables can be considered confounding factors. Previous research in cardiac rehabilitation has indicated that there is poor compliance among women $(13,45)$. One study about the outcome of primary care for patients with back pain found that female gender is a valid predictor of poor outcome (46). On the other hand, married individuals can receive support that enhances compliance. Studies about compliance with back pain and physical therapy treatments did not find a significant link between gender and marital status and compliance $(47,48)$.

We found that poor adherence rates were associated with the presence of other illnesses and also with a longer duration of the therapy. Other researchers $(6,14)$ have found that among the contributors to poor compliance are complexity and length of the therapeutic regimen and the extent of the lifestyle alteration demanded by the treatment. Comorbidity was also found to be a predictor of noncompliance in a study conducted by Lieberman et al. (49) of barriers that are very influential in the coronary patient's decision to participate in a cardiac rehabilitation program. Those researchers found that the existence of a concomi- tant medical illness was one of the three most important obstacles to participation in the program.

There are contradictory results from various studies concerning the association that compliance has with the characteristics, symptoms, disability, and severity of a disease $(9,14,32)$. One study reported by Jones et al. (49) found that low back pain patients who had had previous treatment and persistent symptoms at the time of a follow-up appointment were more likely to comply. Our study did not find that compliance was related to quality of life, intensity of pain, or patients' perceptions of disability. Similarly, a study by Grady et al. (37) of patient compliance after heart transplantation did not predict compliance with such clinical variables as quality of life and functional disability.

There are other factors as well that are related to compliance. In a study that measured adherence to an aerobic regimen, Caserta and Gillett (39) found the following reasons for dropping out: the presence of medical problems, loss of interest, time conflicts, and work pressures. Previous research in cardiac rehabilitation has found that the most common reason cited for not participating in rehabilitation programs was related to transportation $(45,49)$. Studies of compliance with exercise and prevention programs for back pain reported that lack of time was one of the most frequent reasons for noncompliance (43, 50). One study that evaluated compliance among chiropractic patients treated for low back pain showed that work and family responsibilities were the main reasons given by patients for missed appointments (51). Others report that a lack of social support, primarily for elderly people living alone, is a risk factor for nonadherence (52).

In general, depressive symptoms and health beliefs have been reported to influence compliance $(6,10,32)$. However, we found no statistically significant association between compliance and depression and health locus of control beliefs. In investigating compliance with exercise therapy in older participants with knee osteo- arthritis, Rejeski et al. (25) showed that demographic, psychosocial, and disability-related measures did not predict compliance for this group. One study that evaluated health locus of control as a predictor of treatment outcome for patients with low back pain demonstrated that a stronger belief in personal control over back pain was significantly associated with more frequent exercising (29). More studies are needed in this area, specifically targeting short-term supervised compliance with physical therapy treatment.

\section{Limitations of this study}

Assessing the degree of compliance with treatments for low back pain is a problem because there is a lack of standard measures or methods for assessing compliance. There is also a lack of existing specific studies that examine compliance in patients with low back pain. One limitation of this study was perhaps the sample size. However, in an exploratory study, with little guidance to be found in the literature for patients with noncomplicated low back pain, we estimated that a sample size of about 100 patients would be sufficient for generating future hypotheses.

Our study was performed in one clinic with a diversified patient population. The generalizability of the study could be questioned, as is true for all exploratory studies. The treatment performed in this study is common and accepted treatment for noncomplicated low back pain, according to the latest guidelines (15). Nevertheless, as with all exploratory studies, our results should be interpreted with caution if the results are used in other populations.

This study points to the necessity of making a distinction between shortterm compliance and long-term compliance. The two may be different, and they each may require specific strategies to promote treatment adherence among low back pain patients. The lack of stringent definitions for compliance with treatment makes comparisons among studies difficult. 
The results of our study confirm the need for continued research in this area that will hopefully lead to improved treatment compliance in patients diagnosed with noncomplicated low back pain, in both developed and developing countries.

\section{CONCLUSIONS}

The findings of this study support the conclusion that compliance with physical therapy treatment for low back pain is a complex and serious problem that involves multiple variables. The patients in our study demonstrated poor compliance with the recommended program. The dropout rate in attendance at scheduled physical therapy appoint- ments was high, and there were differences in compliance behavior according to each specific treatment regimen.

We found that poor adherence rates were associated with the presence of other medical diagnoses and with longer treatment duration. Some external barriers foreseen by patients were also negatively associated with compliance. The most common expected reasons we found for not following the treatment program were transportation problems, need for child care, and work schedule.

Further research is needed to study in depth these and other compliance barriers. Nevertheless, in spite of the exploratory character of our study, our findings could have practical applications for health care providers who are

\section{REFERENCES}

1. Courtney TK, Webster BS. Disabling occupational morbidity in the United States. J Occup Environ Med 1999;41:60-69.

2. Guo HR, Tanaka S, Halperin WE, Cameron LL. Back pain prevalence in US industry and estimates of lost workdays. Am J Public Health 1999;89:1029-1035.

3. Lindgren B. The economic impact of musculoskeletal disorders. Acta Orthop Scand Suppl 1998;281:58-60.

4. Nordin M, Skovron ML, Hiebert R, Weiser S, Brisson PM, Campello M, et al. Early predictors of delayed return to work in patients with low back pain. J Musculoskel Pain 1997;5: 5-27.

5. Haynes RB, Taylor DW, Sackett DL. Compliance in health care. Baltimore, Maryland, United States of America: Johns Hopkins University Press; 1979.

6. Agras WS. Understanding compliance with the medical regimen: the scope of the problem and a theoretical perspective. Arthritis Care Res 1989;2:S2-7.

7. Baril L. Observance, adherence, compliance ... different words for better therapeutic results. Presse Med 1998;5:13-14.

8. Fawcett J. Compliance: definitions and issues. J Clin Psychiatry 1995;56:4-8.

9. Kroll T, Barlow JH, Shaw K. Treatment adherence in juvenile rheumatoid arthritis-a review. Scand J Reumatol 1999;28:10-18.

10. Becker MH. Patient adherence to prescribed therapies. Med Care 1985;23:539-555.

11. Fodor G, Cutler H, Irvine J. Adherence to nonpharmacologic therapy for hypertension: problems and solutions. Can J Public Health 1998;89:112-115.

12. Greenstein S, Siegal B. Compliance and noncompliance in patients with a functioning renal transplant: a multicenter study. Transplantation 1998;66:1718-1726.
13. Moore SM, Ruland CM, Pashkow FJ, Blackburn GG. Women's patterns of exercise following cardiac rehabilitation. Nurs Res 1998;

14. Turk DC, Rudy TE. Neglected topics in the treatment of chronic pain patients: relapse, noncompliance, and adherence enhancement. Pain 1991;44:5-28.

15. Bigos SJ, Bowyer R, Braen RG, Brown K, Deyo $\mathrm{R}$, Haldeman S, et al. Acute low back problems in adults. Clinical practice guideline. Rockville, Maryland, United States: United States Department of Health and Human Services, Public Health Service, Agency for Health Care Policy and Research; 1994.

16. Lawrence VA, Tugwell P, Gafni A, Kosuwon W, Spitzer WO. Acute low back pain and economics of therapy: the iterative loop approach. J Clin Epidemiol 1992;45:301-311.

17. Burke LE, Dunbar-Jacob JM, Hill MN. Compliance with cardiovascular disease prevention strategies: a review of the research. Ann Behav Med 1997;19:239-263.

18. Sluijs EM, Knibbe JJ. Patient compliance with exercise: different theoretical approaches to short-term and long-term compliance. Patient Educ Couns 1991;17:191-204.

19. Jensen MP, Karoly P, Braver S. The measurement of clinical pain intensity: a comparison of six methods. Pain 1986;27:117-126.

20. Fairbank JCT, Davies JB, Couper J, O'Brien JP. The Oswestry low back pain disability questionnaire. Physiotherapy 1980;66:271-273.

21. MacDowell I, Newell C. Measuring health: a guide to rating scales and questionnaires. New York: Oxford University Press; 1996.

22. Wood-Dauphine S, Williams JI. The Spitzer Quality of Life Index: its performance as a measure. In: Osoba D, ed. The effect of cancer 47:318-324. trying to identify patients likely to become noncompliant. Providers should take these issues into consideration at the time of the first evaluation and attempt, together with the patient, to find alternative strategies for dealing with anticipated difficulties.

Acknowledgements. We are very grateful for the cooperation of physical therapist Katia Costa-Black. We also thank Dr. Dawn Leger for editing the manuscript. This research was partly funded by a grant from the National Institute of Arthritis and Musculoskeletal and Skin Diseases (NIAMS/ 5 RO1 AR 44288 04) of the United States of America and by the Fundação de Amparo à Pesquisa do Estado de São Paulo (FAPESP) of Brazil. on quality of life. Boca Raton, Florida, United States: CRC Press Inc; 1991. Pp. 169-184.

23. Radloff LS. The CES-D Scale: a self-report depression scale for research in the general population. App Psychol Meas 1977;3:385-401.

24. Radloff LS, Locke BZ. The community mental health assessment survey and the CES-D scale. In: Weisman MM, Myers JK, Ross CE, eds. Community surveys of psychiatric disorders. New Brunswick, New Jersey: Rutgers University Press; 1986. Pp. 177-189.

25. Rejeski WJ, Brawley LR, Ettinger W, Morgan $\mathrm{T}$, Thompson C. Compliance to exercise therapy in older participants with knee osteoarthritis: implications for treating disability. Med Sci Sports Exerc 1997;29:977-985.

26. Wallston KA, Wallston BS, DeVillis R. Development of the Multidimensional Health Locus of Control (MHLC) Scales. Health Ed Monogr 1978;6:161-171.

27. Wallston KA, Wallston BS. The construct of health locus of control. In: Sanders GS, Suls J, eds. Social psychology of health and illness. London: Lawrence Erlbaum Associates; 1982. Pp. 65-95.

28. Tait R, DeGood G, Carron H. A comparison of health locus of control beliefs in low back pain patients from the U.S. and New Zealand. Pain 1982;14:53-61.

29. Harkapaa K, Jarvikoski A, Mellin G, Hurri H, Luoma J. Health locus of control beliefs and psychological distress as predictors for treatment outcome in low back pain patients: results of a 3-month follow-up of a controlled intervention study. Pain 1991;46:35-41.

30. Hulley SB, Cummings SR. Designing clinical research. Baltimore, Maryland, United States: Williams \& Wilkins; 1988.

31. StatSoft Inc. STATISTICA for Windows. Tulsa, Oklahoma, United States: StatSoft Inc; 1997. 
32. Mayo NE. Patient compliance: practical implications for physical therapists. Phys Ther 1978; 58:1083-1089.

33. Oldridge NB. Compliance and dropout in cardiac exercise rehabilitation. J Cardiac Rehabil 1984;4:166-177.

34. Friedrich M, Gittler G, Halberstadt Y, Cermak T, Heiller I. Combined exercise and motivation program: effect on the compliance and level of disability of patients with chronic low back pain. Arch Phys Med Rehabil 1998;79:475-487.

35. DiFabio RP, Mackey G, Holte JB. Disability and functional status in patients with low back pain receiving workers' compensation: a descriptive study with implications for the efficacy of physical therapy. Phys Ther 1995;75: 180-193.

36. Lowdermilk A, Panus PC, Kalbfleisch JH. Correlates of low back pain outcomes in a community clinic. Tenn Med 1999;92:301-305.

37. Grady KL, Jalowiec A, White-Williams C. Patient compliance at one year and two years after heart transplantation. J Heart Lung Transplant 1998;17:383-394.

38. Kyngas H, Lahdenpera T. Compliance of patients with hypertension and associated factors. J Adv Nurs 1999;29:832-839.
39. Caserta MS, Gillett PA. Older women's feelings about exercise and their adherence to an aerobic regimen over time. Gerontologist 1998; 38:602-609.

40. Jensen GM, Lorish CD. Promoting patient cooperation with exercise programs. Arthritis Care Res 1994;7:181-189.

41. Shephard RJ. Factors influencing the exercise behaviour of patients. Sports Med 1985;2: 348-366

42. Harkapaa K, Jarvikoski A, Mellin G, Hurri H. Controlled study on the outcome of inpatient and outpatient treatment of low back pain. Scand J Rehab Med 1989;21:81-89.

43. Spelman MR. Back pain: how health education affects patient compliance with treatment. Occup Health Nurs 1984;32:649-651.

44. Donovan JL, Blake DR. Patient non-compliance: deviance or reasoned decision-making? Soc Sci Med 1992;34:507-513.

45. Halm M, Penque S, Doll N, Beahrs M. Women and cardiac rehabilitation: referral and compliance patterns. J Cardiovasc Nurs 1999;13 83-92.

46. Von Korff M, Deyo RA, Cherkin D, Barlow W Back pain in primary care. Spine 1993;18. 855-862
47. Sluijs EM, Kok GK, van der Zee J. Correlates of exercise compliance in physical therapy. Phys Ther 1993;73:771-782.

48. Jones SL, Jones PK, Katz J. Compliance for low back patients in the emergency department. Spine 1988;13:553-556.

49. Lieberman L, Meana M, Stewart D. Cardiac rehabilitation: gender differences in factors influencing participation. J Women's Health 1998;7:717-723

50. Linton SJ, Bradley LA. An 18-month followup of a secondary prevention program for back pain: help and hindrance factors related to outcome maintenance. Clin J Pain 1992;8: 227-236.

51. Beazley DL, Paris DR, Partington JT. Correlates of compliance among chiropractic patients treated for low back pain. J Man Phys Ther 1986;9:125-129.

52. De Geest $\mathrm{S}$, von Renteln-Kruse W, Steeman E, Degraeve S, Abraham IL. Compliance issues with the geriatric population. Nurs Clin North Am 1998;33:467-480.

Manuscript received 4 December 2001. Revised version accepted for publication 24 April 2002.

RESUMEN Objetivos. Aunque se han hecho grandes esfuerzos por encontrar tratamientos eficaces para las lumbalgias, la eficacia de las diferentes modalidades terapéuticas puede depender de su cumplimiento por parte del paciente. El objetivo de este estudio prospectivo consistió en investigar si las características demográficas del paciente, los factores clínicos, los obstáculos externos al cumplimiento del tratamiento y la percepción subjetiva de la discapacidad y la calidad de vida, la depresión y el control sobre la salud permiten predecir el cumplimiento de un programa fisioterapéutico para pacientes con lumbalgia.

Métodos. El estudio, de cohorte, prospectivo y exploratorio, se realizó en la ciudad de Nueva York en 1999. Todos los participantes contestaron un cuestionario durante el examen clínico inicial, realizado por un fisioterapeuta, y fueron seguidos durante el tratamiento. Se investigó el cumplimiento de los tres regímenes terapéuticos prescritos a cada uno de los pacientes, que consistieron en asistir a sesiones programadas de fisioterapia, realizar un programa de ejercicios en su casa y visionar cintas de vídeo educativas sobre la espalda. Dependiendo de cada caso, el programa terapéutico planeado podía durar entre 2 y 6 semanas. Para caracterizar a los pacientes se empleó un conjunto de instrumentos que medían la limitación funcional subjetiva, la calidad de vida, la depresión y las creencias sobre su salud. Para detectar diferencias estadísticamente significativas entre los pacientes no cumplidores o con bajo cumplimiento y aquellos con alto cumplimiento se utilizaron las pruebas de la $t$ de Student y de la $\chi^{2}$. Las razones de probabilidades (odds ratios) ajustadas que expresaban la asociación entre determinadas variables y el cumplimiento se estimaron mediante regresión logística.

Resultados. En términos generales, 51\% de los pacientes incumplieron total o parcialmente el programa terapéutico. Hubo diferencias entre los tres regímenes en lo que se refiere a su cumplimiento; el mayor correspondió a los vídeos educativos y el menor al programa de ejercicios a realizar en casa. El bajo cumplimiento global se asoció de forma positiva a la previsión de obstáculos para seguir el tratamiento propuesto, a la comorbilidad y a la mayor duración del tratamiento.

Conclusiones. Los resultados de este estudio indican que el cumplimiento de los tratamientos de la lumbalgia es un problema serio y complejo. Aunque solo se trató de un estudio exploratorio, los autores creen que sus resultados pueden servir a los profesionales de la salud para identificar a los pacientes con probabilidades de no cumplir el tratamiento, y a los investigadores para planear estudios específicos sobre 
la eficacia de los programas de tratamiento de la lumbalgia. 